\title{
Experiences and Perspectives of Music Therapists Working with Families Experiencing Poverty: A Qualitative Investigation
}

\author{
Jessica June Nagel ${ }^{1}{ }^{*}$, Michael Joseph Silverman ${ }^{1}$ \\ 1 University of Minnesota \\ *jessica.june.nagel@gmail.com
}

Received: 16 February 2017 ; Accepted: 16 May 2017 ; Published: 1 July 2017

Editor: Daphne Rickson Reviewers: Stine Jacobsen, Nicole Rivera

\begin{abstract}
While music therapists have worked with families experiencing poverty, little literature exists concerning music therapy with this population. The purpose of this study was to gain an understanding of the experiences and perspectives of board-certified music therapists who work with families experiencing poverty. Five board-certified music therapists who are currently or have previously worked in settings that primarily served families experiencing poverty participated in semi-structured interviews. Participants reviewed interview transcripts for member checking purposes and later provided feedback on emerging themes. Interviews were analyzed for emerging themes using the six phases of thematic analysis (Braun \& Clark, 2006). Trustworthiness was obtained via the second author who independently reviewed transcripts and created codes and themes. Four themes regarding the use of music therapy interventions with families experiencing poverty emerged: (a) music therapy facilitates the development of parenting skills via education and interaction, (b) children and adults generalize skills from music therapy sessions to daily life, (c) awareness of the factors and unique stressors associated with poverty positively impacts the therapeutic process, and (d) music therapy compliments the broader continuum of support services to meet individual needs. Overall, participants perceived music therapy interventions to be uniquely beneficial in supporting the therapeutic needs of families experiencing poverty. Music therapists can use emerging themes to expediently develop working alliance and potentially create new positions to serve this marginalized population. Implications for practice, limitations, and suggestions for future research are provided.
\end{abstract}

Keywords: poverty, homelessness, music therapy, interviews, thematic analysis

\section{Introduction}

In 2015 , approximately $43 \%$ children experienced poverty in the United States (Jiang, Granja, \& Koball, 2017). Families experiencing poverty are often exposed to unique stressors such as housing instability, poor nutrition, and community violence. Poverty is an inequity that impacts physical and mental health for both children and adults (Buckner, Bassuk, Weinreb, \& Brooks, 1999; Raver, 2004). Psychosocial treatment interventions, including music therapy, may be used on an individual level to decrease 
the effects of stresses related to poverty (APA Taskforce on Socioeconomic Status, 2007; Guarino, 2014).

While music therapists have worked with families experiencing poverty in various settings including homeless shelters (Fairchild, Thompson, \& McFerran, 2017; Iliya, 2011; Straum \& Brotons, 1995; Yates \& Silverman, 2016), community-based organizations (Austin, 2007; Kowski, 2007), schools (Camilleri, 2007; Montello \& Coons, 1998; Snow \& D'Amico 2010), and state-operated facilities (Lotter, 2010), little empirical literature exists concerning music therapy with this group. There is a small but growing body of literature regarding the use of music therapy with at-risk families. For the purposes of this study, "families experiencing poverty" refers to broad scope of issues related to families in a large Midwestern city in the United States who live below the poverty line and are either housed or homeless (APA Taskforce on Socioeconomic Status, 2007; Bassuk, Weinreb, Dawson, Perloff \& Buckner, 1997). The inequities of poverty are a violation of human rights (United Nations Development Programme, 2003) that must be tended to on a broad systemic scale. However, for the purposes of this study, the researchers focus on the possible use of music therapy to create change among individual families experiencing poverty. The purpose of this study was to gain an understanding of the experiences and perspectives of music therapists who work directly with families experiencing poverty.

\section{Families Experiencing Poverty}

Forty-three percent of children in the United States experieinced poverty with their families in 2015 (Jiang, Granja, \& Koball, 2017). Children from low-income families frequently encounter traumatic events such as persistent hunger, anxiety, and witnessing or experiencing violence among others. The effects of trauma often accumulate over time, intensifying reactions to stress with each compounding event. The culmination of adverse events puts low-income children and teens at higher risk than their peers for mental health and developmental challenges. (Buckner, 2008; Cowan, 2014; Donlon, Lake, Pope, Shaw, \& Haskett 2014; Guarino, 2014; Samuels, Shinn, \& Buckner, 2010).

Parents experiencing poverty often face a number of economic and emotional stressors that can detract from their ability to provide consistent and supportive parenting. These stressors may include singleparenthood, social ioslation, substance abuse, and mental illness (Bolen, McWey, \& Schlee, 2008). These factors can leave their children at-risk for developmental difficulties (Foley, 2010). Additionally, poor parent-child interaction, including child abuse and neglect, during infant and toddler years can adversly impact social and emotional development (Bolger, Patterson, Thompson, \& Kupersmidt, 1995; Samuels, Shinn, \& Buckner, 2010; Sroufe, 2005). Chronic negative parenting and frequent exposure to traumatic events can lead to behavior issues (i.e., difficulties with impulse control, self-regulation, and sustatined attention) that can negatively impact children's success in school (Herbers, Cutuli, Monn, Narayan, \& Masten, 2014; Herbers, Cutuli, Supkoff et al., 2014; Masten, 2012; Narayan, Herbers, Plowman, Gewirtz, \& Masten, 2012; Obradovic et al., 2009; Smith, Stagman, Blank, Ong, \& McDow, 2011).

Families experiencing poverty in the United States are disproportionally people of color. In 2015, $63 \%$ of black children, $61 \%$ of Hispanic children, and $61 \%$ of American Indian children lived in low-income families. Immigrant families also represent a disproportionately high population of low-income families, as $52 \%$ of children of immigrant parents experienced poverty in 2015 (Jiang, Granja, \& Koball, 2017). Linguistic and cultural differences can become barriers that keep families experiencing poverty from the available community resources, thus limiting their opportunities to receive mental health services and developmental supports (McCabe, Gilchrist, Harris, Afridi, \& Kyprianou, 2013). Particularly in the United States, systems of discrimination towards families of color over many decades have left urban areas segregated, often 
isolating families of color from educational resources and physical and mental health services (APA Taskforce on Socioeconomic Status, 2007; Cooper \& Masi 2007).

\section{Current Best Practices to Meet the Needs of Families Experiencing Poverty}

Guarino (2014) suggested that service providers working with families experiencing poverty be aware of how trauma impacts behavior, emotions, and attitudes. Traumainformed practice comprises understanding the specific trauma, promoting safety, supporting the client's sense of control/choice/autonomy, sharing power, integrating care, and ensuring cultural competence. Masten (2015) identified that interventions specifically geared towards improving executive functioning and self-regulation skills among children experiencing poverty can reduce problem behaviors and increase school success. It is important to support parents experiencing poverty by teaching positive parenting practices and by offering direct engagement opportunities that promote parentchild bonding (Smith et al., 2011). Parent education groups that teach parents positive control and active listening improve outcomes among their children (Herbers, Cutuli, Supkoff et al., 2014; Yang, 2016). Additionally, there is a growing body of research that has identified mindfulness interventions to improve self-awareness among children and adults with greater self-awareness correlating with improved ability to adapt in adverse situations (Masten, 2015).

\section{Music Therapy and Families Experiencing Poverty}

Music therapists have reported working with low-income families in various settings including homeless shelters (Fairchild, Thompson, \& McFerran, 2017; Iliya, 2011; Straum \& Brotons, 1995; Yates \& Silverman, 2016), other community-based organizations (Austin, 2007; Kowski, 2007), schools (Camilleri, 2007; Montello \& Coons, 1998; Snow \& D'Amico 2010), and state-operated facilities (Lotter, 2010). Music therapists have also reported working with at-risk families to support parent-child interaction among parents and their infants and toddlers (Abad \& Williams, 2007; de l'Etoile, 2006; Jacobsen, McKinny, \& Holck, 2014; Nicholoson, Berthelsen, Adad, Williams, \& Bradley, 2008).

Among the limited music therapy literature for families experiencing poverty, the most common interventions were songwriting (Austin, 2007; Camilleri, 2007; Fairchild, Thompson, \& McFerran, 2017; Kim, 2015; Straum \& Brotons, 1995), music listening (Kim, 2015; Montello \& Coons, 1998), singing (Iliya, 2011), and improvisational instrument playing (Austin, 2007; Kim, 2015; Kowski, 2007; Lotter, 2010; Montello \& Coons, 1998; Snow \& D'Amico 2010). The goals and objectives addressed by music therapists often mirrored the recommended objectives made in related literature; expressing and regulating emotions (Fairchild, Thompson, \& McFerran, 2017; Kim, 2015; Kowski, 2007; Montello \& Coons, 1998), reducing impulsive behaviors (Austin, 2007; Montello \& Coons, 1998), improving social skills (Austin, 2007; Camilleri, 2007; Straum \& Brotons, 1995; Yates \& Silverman, 2016), improving communication (Austin, 2007; Camilleri, 2007; Kim, 2015; Snow \& D'Amico 2010; Yates \& Silverman, 2016), and building academic skills (Yates \& Silverman, 2016).

Due to a lack of empirical research in relation to music therapy and families experiencing poverty, Yates and Silverman (2016) set out to establish a base for future research by conducting a qualitative investigation to understand the needs of children experiencing homelessness as perceived by staff at a homeless shelter. Yates and Silverman (2016) identified four themes: (a) staff need to be positive role models and provide trusting and affectionate relationships, (b) older children require programming and opportunities for communication and emotional support, (c) well-being must be screened and monitored, and (d) routine and expectations are needed to promote a calm living environment. These themes provide insights that music therapists working 
with families experiencing poverty may use to develop goals, objectives, and interventions.

The existing accounts of music therapists working with families experiencing poverty are found in case studies (Austin, 2007; Camilleri, 2007; Kowski, 2007; Lotter, 2010; Snow \& D'Amico 2010), a book chapter (Jacobson, 2016), and empirical research studies (Fairchild, Thompson, \& McFerran, 2017; Montello \& Coons, 1998; Straum \& Brotons, 1995). Although Yates and Silverman (2016) studied the perspectives of homeless shelter staff, there remains a gap in the literature concerning the perspectives and experiences of music therapists who work with this population. Investigation concerning how music therapists work with this specific population is needed to determine appropriate directions for future music therapy research with families experiencing poverty. Therefore, the purpose of this study was to gain an understanding of the experiences and perspectives of board-certified music therapists who work with families experiencing poverty. The primary research question guiding the study was as follows: What are the experiences and perspectives of music therapists working with families experiencing poverty?

\section{Method}

\section{Participants}

Participants were five board-certified music therapists who have previously or are currently working with families experiencing poverty in urban areas in the United States. Three participants had previously worked for a community based non-profit organization that provided services at a multicultural therapeutic preschool and with low-income parent education/support groups. One participant had previously worked at an emergency homeless shelter, providing services to children ages 3-12. One participant currently works in the special education department of a large urban school district and treats many children experiencing poverty. Despite some variance in the specific settings, all participants worked as music therapists with service users who were experiencing poverty in the same city. All participants were female, three were Caucasian, one was black, and one was Japanese-American. In this initial investigation, all participants were previously known to the researchers and had provided music therapy services to families experiencing poverty in the same geographic location in the US. These five music therapists were approached for participation due to their experiences and their familiarity with the researchers. Each participant was individually approached by the principal investigator (PI) and introduced to the study before providing consent to participate in a semi-structured interview which would be audio-recorded, transcribed, and used as qualitative data after removing names to maintain confidentiality. The Institutional Board of Review of the researchers' affiliated university approved the project.

\section{Procedure}

The investigators developed a semi-structured interview (Appendix A) to engage the participating music therapists in conversation about their perspectives and experiences. The interview questions were discussed and conceptualized among a class of music therapy graduate students who provided feedback to help develop the questions, to ensure the interview focused on and addressed the research question, and to minimize biases by identifying and modifying questions that may have been leading or assumptive. The PI conducted four interviews in-person in a quiet, public space, and in order to make the interview more convenient for one particular participant, one interview over the phone. Each interview lasted approximately 60-min. During the interviews, the PI asked the participants to elaborate on and clarify statements to fully understand the participants' experiences and perspectives. All interviews were audio recorded and transcribed by the PI and undergraduate student transcribers. After transcription, the PI initially reviewed the transcripts and identified clarifying questions 
and statements. The PI then shared the transcripts with the participants and asked them to review the data for member checking purposes. At this stage, participants were encouraged to add additional information to the transcripts to ensure the data accurately reflected their experiences and perspectives.

As the goal of the research was to understand and interpret participants' experiences, the researchers used a phenomenological approach. The researchers believed the participants' perceptions were consequential and the goal of the study was to reveal the meanings based on their perceptions of those lived experiences (Laverty, 2003) in working as music therapists with people experiencing poverty.

\section{Qualitative Analysis}

The investigators analyzed the interview transcripts for emerging themes using Braun and Clarke's (2006) six phases of thematic analysis including 1. familiarization with the data, 2. generating initial codes, 3. searching for themes, 4. reviewing themes, 5 . defining and naming themes, and 6 . producing the report. The investigators implemented the six phases as follows: 1 . the investigators repeatedly read the data, 2 . the PI created initial codes, 3 . the related codes were organized into themes in a separate document, 4. the themes were repeatedly reviewed and refined to best represent the data and answer the research question, and 5. themes were named and defined after trustworthiness was obtained via the second author who separately reviewed transcripts and created codes and themes. After the themes emerged, the participants were also contacted to provide feedback on the emerging themes and the quotes used to depict them. Results were then presented at a research poster session at a professional music therapy conference and the authors integrated suggestions made by attendees into the paper. As this was a poster session, some suggestions that attendees made were already in the paper but not on the poster. Other suggestions were included when applicable.

\section{Authors' Lenses and Biases}

At the time of data-analysis, the PI was a board-certified music therapist with six years of experience working with families experiencing poverty, who primarily uses a variety of interventions, including experience-oriented improvisation and songwriting (Baker, 2015) paired with a cognitive behavioral music therapy approach. The second author is a published music therapy educator, researcher, and clinician who specializes in cognitive behavioral music therapy with adult mental health populations. Issues related to poverty are frequently a concern with these clients. Both authors are Caucasian, both live and work in the United States. The current study is specific to families experiencing poverty in the United States and the authors recognize that other countries may have different circumstances and contextual parameters that influence programming, treatments, and poverty. It would be impossible to separate those experiences from the researchers' way of knowing, interpreting, and understanding the data (Edwards, 2012; Stige, Malterud, \& Midtgarden, 2009).

\section{Results}

Four themes emerged during data analysis. These four emerging themes are presented below in boldface font and then explained in the subsequent paragraph. Codes used to categorize data are depicted. Participants' statements are also portrayed to provide contextual support for the themes and honor their unique perceptions, lived experiences, and voices.

\section{Music therapy facilitates the development of parenting skills via education and interaction}

Codes: structure; interaction; reunification; modeling; engagement; provide parent support; positive feedback; enjoyment; comfort 
Participants noted that music therapy interventions facilitated positive parenting skills and appropriate parent/child interaction during the reunification process, during which parents had supervised visits with their children who had been removed from the home due to child protection cases. The participants indicated that low-income parents who engage in group music therapy sessions with their children may successfully practice positive parenting skills and build healthy attachment, while receiving the benefits of peer modeling and positive feedback. Additionally, participants articulated that music therapy groups engaged parents at their developmentally appropriate level, allowing them to comfortably participate and gain parenting and self-care skills.

MT \#1: They were able to actually enjoy their time with their child you know, in a structured environment...I think those [reunifications] environments can also be stressful because they are being observed and watched, but music had a way of making them feel comfortable... [Music therapy group] was a way of strengthening those bonds and showing them healthy and appropriate interactions ... the whole point was to be a model for the moms and to teach them appropriate ways to interact with their child and to increase, improve their bond with their child...For the family groups engaging in appropriate behavior, using appropriate language with each other, gentle touches, that would be a couple [of goals] for the families...if I'm doing a reunification, I would just ask the parents what kind of songs they sing with their child to get their preference. I do remember a lot of the times when I went in-home, it was because the parents need extra support and I would try to teach them appropriate ways to interact with their kid.

MT \# 2: I thought that music could be a non-invasive, least threatening way to communicate best parenting practices regardless of culture... [The moms] could also see the modeling going on, receive some positive feedback, and just kind of be comfortable...I do feel that's why most of them didn't want to run away from music. For most of them, even to just get on the floor and just play with their children is one of the hardest things for them, because they've never seen it modeled...Without a television going on, without any kind of distraction, but just kind of sitting and playing, and talking, and singing with their children, having that kind of contact. So that kind of communication and relationship building was really good...Even if it's something like hand over hand, "help your baby do this". Eye contact with the mother, so that the mother can initiate eye contact with her child. So the primary focus is on the mother so that they can mother their child, you praise, you give feedback for all of the successive approximations that they are accomplishing.

MT \#3: I did individual mommy/baby time within the groups and I did the same sort of things like 'This is what we did today and these are things that you can do,' or I could talk to the parents about developing goals for their kiddos too, I was just wanting to engage the parents. My goal was to have a good conversation about ways to be playful with their kids. You know, we're going to be there for a blip in their life, especially when they're so transient, who knows how long they're going to be in this program? So, if we can give parents skills, I feel like that's really important... When the kids were in foster care and they would visit their parents...if the family requested it or if the social workers thought that they needed another person to structure the time and make it successful, they would have me come in and I would do a family music therapy time. And that would be just these same goals of like interaction, nurturing touches and words, and parent education

MT \#4: It really let the parents get to see and have fun with their child, which was so important... When you've had parents who had been separated from their children, I just think that opportunity to structure positive interactions where the focus is on the child becomes a really key thing....And I think by having a music therapist in the shelters and in the community programs and in the parenting programs, you get a chance, rather than being talked at, you get a chance to really set up the group...You model, "Let the child have a turn! My turn, your turn!"

\section{Children and adults generalize skills from music therapy sessions to daily life \\ Codes: Transfer, generalize, interactive music activities; practical; take home; adapt}

In addition to supporting parenting skills, the participants noted that music therapy interventions also provided an opportunity for siblings to practice healthy interactions that generalized to what may be a chaotic home life. The participants expressed that music therapists can provide practical music-based interventions that can directly 
transfer to use at home to improve relationships/attachments for parents/children and siblings. By creating song books or CDs, families can receive a tangible resource to transfer skills from music therapy sessions to home or other settings. The participants expressed that music therapists can engage parents by brainstorming ways to adapt music games and activities for use at home or other settings. Also, the participants noted that a music therapist can suggest "homework" for children and adults to practice non-music skills outside of the music therapy session.

MT \#1: With the mom and babies it was more like lap play, bouncy games, lots of parachute, and lullabies, bubbles. With that group you want to be more practical, because you want them to practice with their babies at home. Of course you're going to have things that they're not going to have, but you have to teach them how to adapt....The sibling groups didn't involve a lot of manipulatives because we did want them to practice at home, so I think we did a lot of, dance and songs that they could sing together ... With music therapy, for a lot of families it's so simple to incorporate in real life - you know, you learn some finger play or a lap game or any of that, so all that stuff that you can do and you don't need stuff to do it.

MT \#2: Really encouraging the parents and talking about how they could use music with their kids, how can you put that on the table and how can you make that connection.

MT \#3: A lot of these siblings would benefit from extra support and working together. These are the goals I was trying to do, working together or using words, problem solving, so when they go home, if it is not a safe environment, they can maybe work with each other and figure out things and have a solid bond together...And then I would give them those visuals and we would make a book, then they could take the book home. So for the siblings, I liked to give them something to take home, as like a really cognitive, concrete thing of like "We're taking these skills home!" ...I would do songwriting with the families, and I could record it right then, burn a copy of the CD and they could have it, and that was something really meaningful. With the little babies I would have a little sheet of like 'these are the things we did today, these are some other things that you could do along the same lines.' So they had some materials because "I can't be here every time you have visitation, but here are some ideas and then you can do it yourself next time." So I'd try to give the parents tools and I think they appreciated that.

MT \#4: Instead of having the child go to school and then go home and no generalization, having that opportunity for that parent/child together in a real world, which is to me what music therapy can do.

\section{Awareness of the factors and unique stressors associated with poverty positively impacts the therapeutic process}

Codes: Immediate success, context, awareness; diversity; abuse/neglect; choice; linguistic diversity; minorities/immigrants; generational; factors associated with race; cultural sensitivity

The participants noted music therapy group sessions may be particularly engaging for diverse populations because culturally and linguistically specific music can be incorporated while working towards goals. The participants indicated that awareness of common issues related to cultural and linguistic diversity (including English language learners, non-English speakers, or non-English readers) may impact the therapeutic outcomes. As navigating the available community resources can be a frustrating and daunting task for low-income families, the participants noted that because music therapy can be a non-intimidating intervention, both children and adults may benefit from the opportunity to experience immediate success in music therapy. The prevalence of abuse and neglect cases, chemical dependency, and mental health issues is high among the population of families experiencing poverty and the participants indicated that awareness of the social, emotional, and developmental factors related to these issues can also impact the therapeutic process. The participants also expressed that awareness of the barriers was crucial when working across racial, cultural, and socio-economic lines. Participants noted these factors may impact the development of 
the therapeutic relationship as many families experiencing poverty are people of color and/or recent immigrants, while music therapists in the US are predominantly white.

MT \#1: There were definite differences between the cultures.... I think, a lot of times, what scares people about working with this population is that they don't know about it...So I'm not saying that you can't be Caucasian to work with people in poverty, I'm just saying have awareness and cultural sensitivity and just knowing about the population and what they are going through and why they don't know their ABCs, they are too worried about feeding them.

MT\#2: As music therapists, we're trained to do that; we want everyone participating to actually be fairly successful almost immediately and then you can work with them. Music therapy was just nonthreatening, it was a really comfortable way and an easy way for people to get some success. If you can go in and be open and flexible, and listen, then it will bridge practically everything. Just laying aside my own expectations and really going into the family care. In providing culturally sensitive therapy and programs, I think music was a perfect addition.

MT \#3: A lot of the kids had mild to moderate delays, we had some kids that had diagnoses, there were some that were on the spectrum, there were some that had exposure in utero to drugs or alcohol, so there were some delays in that way. There was some abuse that had occurred and then resulted in traumatic brain injuries or shaken baby syndrome, you know, those kind of things, or falling down steps, neglect...There were a lot of child protection cases open with their families, and a lot of the moms that went to our parenting programs were court mandated to go to them.... These parents were products of this cycle also, and so just another way that music really can make it successful because they can anticipate what I'm doing and it's repetitive.

MT \#3: Like for everybody, this is something that everybody can do and experience and find enjoyment in. I can have these large community-type groups and serve so many people that may not have a common language and yet they're all doing something together, and that's a pretty cool thing ...I think it makes perfect sense for there to be music therapy, because we have such a diverse group of families, language wise, experience wise, socio-economic wise, but music is something we can all do, and it really evens the playing field... I could easily add a cultural aspect. We would do something every time there was some kind of cultural celebration I was there, you know, because it was a way that I could serve and help.

MT \#4: Lack of experience and awareness of things that you might take for granted--that's one of the biggest differences I think when you're working with students of poverty. You don't necessarily know what the student is coping with...We know students of poverty come into school with three million less words...Children really parallel their parents' language, and so when you have meetings and you're talking to parents, you really have to be sure you're communicating, or you will just wash over them and they won't understand what you're doing or trying to do for their child ... So it's probably just that awareness factor as much for when we're working with parents if we want to impact what they're doing with their children.

MT \#5: So music was something that most of them could be instantly successful at. It was great to see them be successful and interact with each other, and also use skills that they didn't know they have...it's just a chance to be expressive in a way that was really safe.

\section{Music therapy compliments the broader continuum of support services to meet individual needs}

Codes: Fills gap, collaboration, unique, holistic, flexible

The participants indicated that music therapy interventions can provide a unique, alternative modality to meet individual and collective needs. The participants noted that music therapy can provide support through direct collaboration between practitioners or through reinforcing goals worked on in different therapeutic modalities. During the interviews, participants articulated that collaboration between service providers may be particularly easy for music therapists due to the inherent flexibility of music. The participants expressed that children and adults benefit from music therapy intervention that supports overall outcomes (i.e., chemical dependency recovery 
and developmental and educational goals) by bridging the gap between other service providers.

MT \#1: I think families liked having music therapy because it was different. It's so nonthreatening... Everyone learns differently, you know. It was kind of a well-rounded approach to helping them reach the level they needed to reach...I think music therapists are just another piece of that puzzle that can help the families... It was just a different modality to occupational, physical or speech. And it was really nice, as music therapists we can work together, we can collaborate with all the other therapies ... Sometimes collaboration didn't necessarily have to be a planned thing.

MT \#2: So music is such a malleable tool. They were not looking for music as rigidly as they would have looked at OT [occupational therapy] or speech [therapy] or PT [physical therapy], they saw it as a much less invasive, much more conducive way to just reach some overall goals. Very appropriate for everyone to participate in... With just adult groups, it was a feeling of a kind of actual physical relief that comes from the drumming, from the entrainment. From the little bit of aerobics that they would do, a little bit of brain stimulation. And the other part was just building community.

MT \#3: I definitely collaborated with the OTs, the speech language, the PTs, and teachers...Always communicating with them and the social workers and play therapists. I'd communicate with them a lot. I would go out with the social or family workers when they would do a home visit... Whenever I'd be making goals I'd go to the teachers, I'd meet with them ...I think they appreciated that I wasn't just like making these goals without talking to them and, you know, that there was a mutual respect happening.

MT \#5: Music therapy seemed to really fit with what the shelter's goals are. They definitely want more than just [recreational] music time. Especially given how fragile that community is and how high-risk they are, I think it makes a lot more sense than having someone else come in, because it's a huge adjustment for going from like living with another family prior to becoming homeless or however they became homeless

\section{Discussion}

The purpose of this study was to gain an understanding of the experiences and perspectives of board-certified music therapists who work with families experiencing poverty.

Five US-based board-certified music therapists participated in semi-structured interviews. The investigators analyzed the interview transcripts and identified four emerging themes: (a) music therapy facilitates the development of parenting skills via education and interaction, (b) children and adults generalize skills from music therapy sessions to daily life, (c) awareness of the factors and unique stressors associated with poverty positively impacts the therapeutic process, and (d) music therapy compliments the broader continuum of support services to meet individual needs.

All participants perceived music therapy to uniquely benefit families experiencing poverty, particularly within the context of parent education. Music therapy group sessions can improve parent-child attachment while providing an opportunity to practice positive parenting skills with support from peers and the music therapist (Abad \& Williams, 2007; Herbers, Cutuli, Supkoff et al., 2014; Jacobsen, McKinny, \& Holck, 2014; Smith et al., 2011; Yang, 2016). According to the study participants, music therapy group sessions may also be used to help facilitate the reunification process among families who have been separated due to child protection cases. Both children and adults benefit from the structure provided within music therapy interventions as the nature of music often allows for rhythmic repetition of ideas and actions (Yates \& Silverman, 2016). The participants expressed that music therapy may also provide an opportunity for parents to see appropriate behaviors modeled by peers and by the music therapist within the context of familiar songs and activities, making it easy for individuals to be successful.

The results of the present study compliment and expand upon the emergent themes identified by Yates and Silverman (2016). Although Yates and Silverman's (2016) investigation focused specifically on the needs of children experiencing homelessness from the perspective of non-music therapists (and the present study approached fami- 
lies experiencing poverty on broader scale using music therapists as participants), the conceptual links between the two sets of results may be considered together in the development of music therapy practices. The present study identified the importance of structured routine and opportunities to observe appropriate behaviors modeled by peers and music therapists that is consistent with Yates and Silverman (2016). Additionally, Yates and Silverman (2016) recognized the importance of relationship building to develop a strong working alliance. The present study supplemented that idea noting the clinicians' awareness of factors associated with poverty may help establish a relationship and strong rapport.

\section{Implications for Music Therapy Practice}

Clinicians may use the themes identified in this study to expediently develop working alliance, trust, and rapport with families experiencing poverty. Particularly, the awareness of factors related to poverty and the implementation of trauma-informed practice may help facilitate positive outcomes for this population (Guarino, 2014; Yates \& Silverman, 2016). Music therapists may benefit from opportunities to develop cultural competence in relation to issues associated with poverty. This could take place within university curriculum, practicum experiences with this population, or conference presentations on music therapy best practices with families experiencing poverty.

Music therapists may consider how issues of race and culture impact their working alliance and rapport particularly when Caucasian music therapists are engaging with predominately communities of color. Developing an awareness of culturally specific music traditions and connecting with community musicians may positively impact the therapeutic process (Oosthuizen, Fouche, Torrance, 2007).

Based on the emerging themes, there may be potential for the creation of music therapy positions serving this population. The participants outlined specific ways that music therapy can address the goals of parent-support and education groups and early childhood education groups often provided by community-based non-profits and government-run institutions.

\section{Limitations}

The five participants in this study all shared experiences working within the same large, Midwestern city. Thus, the current study provided a limited perspective on poverty only within a specific urban context in the United States. Additionally, although all five participants had music therapy experience with families experiencing poverty, their work settings differed and represents a limitation. While the current study provided insights from music therapists who have experience working with families experiencing poverty in a variety of settings in the same city, additional research might provide a broader perspective on the experiences of music therapists working with low-income families.

The study is also limited, as it did not investigate potential disadvantages or contraindications of using music therapy when working with families experiencing poverty. The semi-structured interviews were specifically designed to answer the narrow research question. Moreover, the results are limited by the authors' biases resulting from their previous practice, research, educational experiences, and geographic location.

Additionally, as race and culture play a significant role in the experience of poverty in the United States, it should be noted that the authors recognize their perspectives as Caucasian individuals results in inherent biases during interpretation and reporting of the data presented in this study.

\section{Suggestions for Future Research}

Future researchers may consider investigating how music therapy functions in the context of parent education and parent support with families experiencing poverty. For example, investigators, could observe positive parenting behaviors exhibited within a 
music therapy session or interview parents to identify how they perceived music therapy to support their parenting skill development. Additionally, researchers could investigate how music therapy impacts working alliance among clinicians and families experiencing poverty. Understanding how to develop a stronger working alliance may lead better outcomes for this population. Researchers may also consider investigating how to best prepare music therapists and music therapy students to meet the multifaceted needs of this unique and marginalized population. For example, researchers may investigate how a music therapy practicum experience with this population impacts a student's awareness of the factors associated with poverty. Additionally, researchers may compare cultural competency training among related professions such as art therapists, occupational therapists, as well as parent-educators and early-childhood teachers. Future researchers may consider interviewing music therapists from diverse regions to compare their perspectives working with families experiencing poverty. Further research identifying the links between music therapy and positive outcomes among families experiencing poverty could be used as rationale for developing new music therapy positions. Finally, results of this qualitative study could be used in future quantitative studies by designing interventions to target identified factors including parenting skills, interactions between parents and children, and stressors.

\section{Conclusion}

The purpose of this study was to gain an understanding of the perceptions and experiences of music therapists who work with families experiencing poverty. The themes that emerged from this study provide unique insights into how music therapy may be used to meet the needs of this population. Future research, honoring all modes of inquiry, is needed to determine if and how music therapy interventions might benefit families experiencing poverty.

\section{References}

Abad, V., \& Williams, K. E. (2007). Early intervention music therapy: Reporting on a 3-year project to address needs of at-risk families. Music Therapy Perspectives, 25, 52-58, https://doi.org/10.1093/mtp/25.1.52.

American Psychological Association, Task Force on Socioeconomic Status. (2007). Report of the APA Task Force on Socioeconomic Status. Washington, DC:American Psychological Association.

Austin, D. (2007). Lifesongs: MT with adolescents in foster care. In V. A. Camilleri (Ed.), Healing the inner city child: Creative arts therapies with at-risk youth (pp. 92-103). Philadelphia, PA: Jessica Kingsley Publishers.

Baker, F. A. (2015). Therapeutic songwriting: Developments in theory, methods, and practice. London: Palgrave Macmillan. https://doi.org/10.1057/9781137499233.

Bassuk, E. L., Weinreb, L. F., Dawson, R., Perloff, J. N., \& Buckner, J. C. (1997). Determinants of behavior in homeless and low-income housed preschool children. Pediatrics, 100, 92-100, https://doi.org/10.1542/peds.100.1.92.

Bolen, M. G., McWey, L. M., \& Schlee, B. M. (2008). Are at-risk parents getting what they need? Perspectives of parents involved with child protective services. Clinical Social Work Journal, 36, 341-354, http://dx.doi.org/10.1007/s10615-008-0173-1.

Bolger, K. E., Patterson, C. J., Thompson, W. W., \& Kupersmidt, J. B. (1995). Psychosocial adjustment among children experiencing persistent and intermittent family economic hardship. Child Development, 66, 1107-1129, http://dx.doi.org/10.2307/1131802.

Braun, V., \& Clarke, V. (2006). Using thematic analysis in psychology. Qualitative Research in Psychology, 3, 77-101, http://dx.doi.org/10.1191/1478088706qp063oa.

Buckner, J. C. (2008). Understanding the impact of homelessness on children: Challenges and future research directions. American Behavioral Scientist, 51, 721-736, http://dx.doi.org/ $10.1177 / 0002764207311984$. 
Buckner, J. C., Bassuk, E. L., Weinreb, L. F., \& Brooks, M. G. (1999). Homelessness and its relation to the mental health and behavior of low-income school-age children. Developmental Psychology, 35(1), 246-257, https://doi.org/10.1037/0012-1649.35.1.246.

Camilleri, V. A. (2007). Therapy with inner city, at-risk children. In V. A. Camilleri (Ed.), Healing the inner city child: Creative arts therapies with at-risk youth (pp. 57-72). Philadelphia, PA: Jessica Kingsley Publishers.

Cooper, J. L., \& Masi, R. (2007). Child and youth emergency mental health care: A national problem. New York: National Center for Children in Poverty, Columbia University Mailman School of Public Health.

Cowan, B. A. (2014). Trauma exposures and mental health outcomes among sheltered children and youth ages 6-18. In M. E. Haskett, S. Perlman, \& B. A. Cowan (Eds.), Supporting families experiencing homelessness, current practices and future directions (pp. 84-123). New York, NY: Springer Science + Business Media. https://doi.org/10.1007/978-1-4614-8718-0_3.

de l'Etoile, S. K. (2006). Infant-directed singing: A theory for clinical intervention. Music Therapy Perspectives, 24, 22-29, https://doi.org/10.1093/mtp/24.1.22.

Donlon, P., Lake, J., Pope, E., Shaw, C., \& Haskett, M. E. (2014). Community action targeting children who are homeless (CATCH): Addressing the mental health and developmental needs of children experiencing homelessness. Families in Society: The Journal of Contemporary Social Services, 95(3), http://dx.doi.org/10.1606/1044-3894.2014.95.21.

Edwards, J. E. (2012). We need to talk about epistemology: Orientations, meaning, and interpretation within music therapy research. Journal of Music Therapy, 49, 372-394, http://dx.doi.org/10.1093/jmt/49.4.372.

Fairchild, R., Thompson, G., \& McFerran, K. S. (2017). Exploring the meaning of a performance in music therapy for children and their families experiencing homelessness and family violence. Music Therapy Perspectives, 35, 1-14.

Foley, K. P. (2010). Parents with major life stressors. In C. B. McNeil \& T. L. Hembree-Kigin (Eds.), Parent-child interaction therapy (pp. 341-362). New York, NY: Springer.

Guarino, K. M. (2014). Trauma-informed care for families experiencing homelessness. In M. E. Haskett, S. Perlman, \& B. A. Cowan (Eds.), Supporting families experiencing homelessness, current practices and future directions (pp. 247-291). New York, NY: Springer Science + Business Media.

Herbers, J. E., Cutuli, J. J., Monn, A. R., Narayan, A. J., \& Masten, A. S. (2014). Trauma, adversity, and parent-child relationships among young children experiencing homelessness. Journal of Abnormal Child Psychology, 42, 1167-1174, https://doi.org/10.1007/ s10802-014-9868-7.

Herbers, J. E., Cutuli, J. J., Supkoff, L. M., Narayan, A. J., \& Masten, A. S. (2014). Parenting and coregulation: Adaptive systems for competence in children experiencing homelessness. American Journal of Orthopsychiatry, 84(4), 1167-1174, https://doi.org/10.1007/ s10802-014-9868-7.

Iliya, Y. A. (2011). Singing for healing and hope: Music therapy methods that use the voice with individuals who are homeless and mentally ill. Music Therapy Perspectives, 29, 14-22, https://doi.org/10.1093/mtp/29.1.14.

Jacobson, S. L. (2016). Child protection: Music therapy with families and emotionally neglected children. In S. L. Jacobson \& G. Thompson (Eds.), Music therapy with families: Therapeutic approaches and theoretical perspectives (pp. 199-220). Philadelphia, PA: Jessica Kingsley.

Jacobsen, S. L., McKinny, C. H., \& Holck, U. (2014). Effects of a dyadic music therapy intervention on parent-child interaction, parent stress, and parent-child relationship in families with emotionally neglected children: A randomized controlled trial. Journal of Music Therapy, 51, 310-332, https://doi.org/10.1093/jmt/thu028.

Jiang, Y., Granja, M. R., \& Koball, H. (2017). Basic facts about low-income children: Children under 18 Years, 2015. New York: National Center for Children in Poverty, Columbia University Mailman School of Public Health. 
Kim, J. (2015). Music therapy with children who have been exposed to ongoing child abuse and poverty: A pilot study. Nordic Journal of Music Therapy, 24, 27-43, https://doi.org/ 10.1080/08098131.2013.872696.

Kowski, J. (2007). “Can you play with me?”: Dealing with trauma, grief and loss through analytical music therapy and play therapy. In V. A. Camilleri (Ed.), Healing the inner city child: Creative arts therapies with at-risk youth (pp. 104-118). Philadelphia, PA: Jessica Kingsley Publishers.

Laverty, S. M. (2003). Hermeneutic phenomenology and phenomenology: A comparison of historical and methodological considerations. International Journal of Qualitative Methods, 2(3), https://doi.org/10.1177/160940690300200303.

Lotter, C. (2010). Music therapy with high risk youth: An international perspective. In C. L. Norton (Ed.), Innovative interventions in child and adolescent mental health (pp. 75-90). New York, NY: Routledge.

Masten, A. S. (2012). Risk and resilience in the educational success of homeless and highly mobile children: Introduction to the special section. Educational Researcher, 41(9), 363-365, https://doi.org/10.3102/0013189X12467366.

Masten, A. S. (2015). Ordinary magic: Resilience in development. York, NY: The Guilford Press.

McCabe, A., Gilchrist, A., Harris, K., Afridi, A., \& Kyprianou, P. (2013). Making the links: Poverty, ethnicity and social networks. Perth, UK: University of Birmingham, Joseph Rowntree Foundation.

Montello, L., \& Coons, E. E. (1998). Effects of active versus passive group music therapy on preadolescents with emotional, learning, and behavioral disorders. Journal of Music Therapy, 35, 49-67.

Narayan, A. J., Herbers, J. E., Plowman, E. J., Gewirtz, A. H., \& Masten, A. S. (2012). Expressed emotion in homeless families: A methodological study of the five-minute speech sample. Journal of Family Psychology, 26, 648-653.

Nicholson, J. M., Berthelsen, D., Adad, V., Williams, K., \& Bradley, J. (2008). Impact of music therapy to promote positive parenting and child development. Journal of Health Psychology, 13(2), 226-238.

Obradovic, J., Long, J. D., Cutuli, J. J., Chan, C. K., Hinz, E., Heistad, D., \& Masten, A. S. (2009). Academic achievement of homeless and highly mobile children in an urban school district: Longitudinal evidence on risk, growth,and resilience. Development and Psychopathology, 21, 493-518.

Oosthuizen, H., Fouche, S., \& Torrance, K. (2007). Collaborative work: Negotiations between music therapists and community musicians in the development of a South African community music therapy project. Voices: A World Forum for Music Therapy, 7(3), http://dx.doi.org/10.15845/voices.v7i3.546.

Raver, C. C. (2004). Placing emotional self-regulation in sociocultural and socio- economic contexts. Child Development, 75, 346-353, http://dx.doi.org/10.1111/ j.1467-8624.2004.00676.x.

Samuels, J., Shinn, M., \& Buckner, J. C. (2010). Homeless children: Update on research, policy, programs, and opportunities. Prepared for the Office of the Assistant Secretary for Planning and Evaluation, U.S. Department of Health and Human Services.

Snow, S., \& D'Amico, M. (2010). The drum circle project: A qualitative study with at-risk youth in a school setting. Canadian Journal of Music Therapy, 16(1), 12-39.

Smith, S., Stagman, S., Blank, S., Ong, C., \& McDow, K. (2011). Building strong systems of support for young children's mental health: Key strategies for states and a planning tool. New York, NY: National Center for Children in Poverty, Mailman School of Public Health, Columbia University.

Straum, M. J., \& Brotons, M. (1995). Issues in music for children in a homeless shelter: Social objectives and choices for reinforcement. Journal of Music Therapy, 32, 248-264, https://doi.org/10.1093/jmt/32.4.248. 
Stige, B., Malterud, K., \& Midtgarden, T. (2009). Toward an agenda for evaluation of qualitative research. Qualitative Health Research, 19, 1504-1516, http://dx.doi.org/10.1177/ 1049732309348501.

Sroufe, L. A. (2005). Attachment and development: A prospective, longitudinal study from birth to adulthood. Attachment \& Human Development, 7(4), 349-367, http://dx.doi.org/ 10.1080/14616730500365928.

United Nation Development Programme (2003) Poverty reduction and human rights: A Practice Note. New York, NY: Author

Yang, Y. H. (2016). Parents and young children with disabilities: The effects of a home-based music therapy program on parent-child interactions. Journal of Music Therapy, 53, 27-54, https://doi.org/10.1093/jmt/thv018.

Yates, G., \& Silverman, M. J. (2016). Needs of children experiencing homelessness who are living in shelters: A qualitative investigation of perceptions of care workers to inform music therapy clinical practice. Voices: A World Forum for Music Therapy, 16(3), https://doi.org/ 10.15845/voices.v16i3.887. 